\title{
El tiempo histórico y la ruralidad en el Perú ${ }^{1}$
}

\author{
Óscar Castillo Rivadeneira \\ Investigador independiente, lima, Perú \\ omcastillor830@gmail.com
}

\begin{abstract}
RESUMEN
Este ensayo se propone algunas pistas para establecer una periodización en la definición del espacio rural en el Perú; a partir de las mediciones cuantitativas realizadas desde fines de los años treinta del siglo pasado, las que se repetirán desde los censos nacionales siguientes.

En la definición de lo rural, un factor clave es la población, residente en localidades, villorrios o comunidades, con menos de dos mil habitantes (según la definición de los Censos en el Perú), pero no deberá ser el único factor, dado que el espacio rural incorpora los procesos de producción y reproducción social, la cultura y las costumbres locales.

También se debe considerar, un tema que es más complejo de demostrar, la relación entre el campo y la ciudad; tal relación es definida por algunos autores como la «nueva ruralidad». En forma esquemática, el ensayo sugiere tres momentos (¿periodos?) en los que se pueden identificar factores o elementos para definir la ruralidad en el Perú: i) 1900-1940, ii) 1940-1970 y iii) 1970- 2010.
\end{abstract}

Palabras clave: Tiempo histórico, territorio rural, nueva ruralidad

\section{Historical time and rurality in Peru}

\begin{abstract}
This essay intends to analyse some clues to establish a period regarding the definition of Ru ral Space in Peru; from the quantitative measurements made since the end of the 30s of the last century, and that will be repeated considering the following national information gathering. In the definition of the rural, a key factor is the population, resident in localities, villages or communities, with less than two thousand inhabitants (according to the definition of the Censuses in Peru), but it should not be the only factor, given that the Rural Space incorporates the processes of social production and reproduction, culture and local customs.

It should also be considered, an issue that is more complex to demonstrate, the relationship between the countryside and the city; such relationship is defined by some authors as the "new rurality». Schematically, the essay suggests three moments (periods?) in which factors or elements can be identified to define rurality in Peru: i) 1900-1940, ii) 1940-1970, and iii) 1970-2010.
\end{abstract}

KeYworDs: Historical time, rural territory, new rurality

1 Agradezco los comentarios del profesor Fernando Armas, del Posgrado en Ciencias Sociales de la Universidad Nacional Mayor de San Marcos. 


\section{Introducción}

El tiempo histórico es una construcción que propone el investigador social, desde la Sociología, la Historia o la Antropología, para situar o contextualizar los eventos y acontecimientos. Desde la Sociología, se plantea el problema de ¿cómo entender la ruralidad en el Perú?, ¿qué es lo rural y que es lo urbano?, ¿cómo se han construido esos conceptos y cuál es su actualidad? En la definición los conceptos se articulan variables o categorías tales como: espacio o territorio, población, división social del trabajo, comunicación, cultura. Se pueden establecer «ciclos» o periodos en la ruralidad: a comienzos del siglo xx, en los años sesenta, y a partir del 2000. ¿Es el mismo concepto? qué elementos condicionan su evolución?

\section{El tiempo histórico y la Sociología}

Uno de los conceptos de mayor debate en la Historia, es acerca del tiempo. Se reconoce que el tiempo real es distinto al tiempo histórico, el cual solo es una construcción que realiza el historiador para asignar un marco temporal a su objeto de estudio. (Ceballos \& y Ceballos, 2006). De allí que, el tiempo en el análisis histórico, será diferente al tiempo de la Física, para el primero el tiempo es una construcción social. (Rajchenberj \& Lambert, 2002)

Según Ceballos y Ceballos (2006), la sucesión histórica se puede analizar, desde dos posiciones temporales.

a) Desde un tiempo cronológico, en base a la datación y ordenación de los acontecimientos seleccionados, para describir cuantitativamente los hechos y, relacionar la evolución histórica. Dicho enfoque supone una sucesión lineal irreversible y una equivalencia de la Historia como memoria escrita, que incorpora y acumula los nuevos acontecimientos relacionados con el sujeto histórico y sus intereses.

b) Desde la definición de un tiempo rizomático como una simultaneidad de posibilidades, que se interrelacionan entre ellas, a modo de espirales. Desde este enfoque se puede observar una simultaneidad de eventos, lo cual permitirá un estudio sincrónico particular, junto con otros acontecimientos anteriores, paralelos y/o posteriores. (Ceballos \& y Ceballos, 2006)

De otro lado, los mencionados autores consideran que el concepto de período, está presente desde el siglo XIx, como una categoría temporal de trabajo del historiador, mediante la objetivación, la cuantificación y la ordenación de los acontecimientos; estableciendo relaciones causales desde el presente. Sin embargo, al introducir la tecni- 
ficación en la actuación del agente histórico, el éxito de cualquier decisión dependerá del momento favorable para la misma, dada por el contexto, tanto presente, pasado, o futuro. En otras palabras, el concepto de periodo, usado para delimitar el tiempo y el espacio de un evento social, es también una construcción elaborada por el historiador, desde el presente, como una herramienta para conocer el pasado histórico.

Desde un enfoque Sociológico, algunos autores, como (Rajchenberj \& Lambert, 2002) analizan el tiempo, en el marco de la evolución del proceso anterior y posterior al surgimiento del capitalismo y la industrialización, como factores que condicionan y modifican el contexto, en el cual los distintos actores sociales, construyeron su noción del tiempo.

Señalan que la visión tradicional de los historiadores, de considerar el tiempo como «una sucesión de fechas», fue superada de manera sustantiva por Marc Bloch, desde la Escuela de los Annales, introduciendo nuevos objetos de estudio tales como la historia del clima, historia de los precios, historia de la vida cotidiana, etcétera. La nueva forma de abordar el tiempo proponía una nueva metodología para comprender la duración diferente de los diversos procesos históricos (culturales, económicos, políticos) y fue la puerta de entrada teórica a la problematización del tiempo; en donde la idea de continuum, establecerá un lazo entre el pasado el presente y el futuro. Así, cada sociedad o grupo cultural, construye la forma como se articulan estos tres factores, claves en su desempeño. Según (Rajchenberj \& Lambert, 2002) para los sociólogos, la conceptualización del tiempo «sólo se puede entender mediante ejemplos históricos; de otro modo, la sociología se vuelve filosofía...»

En conclusión, se pueden destacar algunos conceptos y categorías que serán útiles, para un análisis sociológico, que busque comprender los problemas sociales contemporáneos, estableciendo un continuum entre pasado, presente y futuro. Reconociendo que el tiempo es una construcción social; a su vez, que el tiempo histórico lo define el investigador, un tiempo en el cual se pueden establecer periodos históricos, periodos que podrían tener enfoques y resultados distintos, según se identifiquen las relaciones causales desde el presente o se analicen desde la actuación misma del agente histórico.

\section{Lo rural y lo urbano}

Los conceptos de lo rural y lo urbano en la mayoría de la literatura, están ligados, el primero no se puede entender sino se adopta una definición de lo segundo (Danert \& y Flowers, 2012), de manera general lo rural se asocia con la campińa, los paisajes agrícolas, o villorrios ubicados a largas distancias de los caminos y carreteras principales, así como la carencia de los servicios básicos como el agua y saneamiento y, la energía eléctrica. ${ }^{2}$

2 «..Cuando se piensa en la palabra rural, lo que viene a la mente son los paisajes agrícolas, bosques 
En las zonas rurales, las esferas económicas, sociales, ambientales y culturales tienden a estar estrechamente relacionadas $y$, muchas personas viven cerca de los recursos naturales, de los que dependen directamente para su supervivencia. Sin embargo, también se debe observar que a pesar de la pobreza en que sobreviven los villorrios, caseríos y comunidades rurales, entre ellos existen factores de diferenciación. (Danert \& y Flowers, 2012). En efecto, distintos autores también han analizado los conflictos que se producen entre las propias comunidades, por la fragmentación de los minifundios o la disminución de la capacidad de las tierras productivas (Martinez, 1983) o el surgimiento de nuevos grupos de poder local, luego de la reforma agraria (Euguren, 1989) ${ }^{3}$ o conflictos con sus vecinos más cercanos, por problemas de lineros o límites de los territorios..

\subsection{Las definiciones del área rural y la población rural}

La urbanización y la ruralidad, son espacios socialmente construidos por la humanidad. En ese sentido sus definiciones tendrán variaciones según el periodo que se quiera investigar. Es probable que en el desarrollo de las sociedades los espacios rurales y urbanos registren procesos continuos de larga duración, o surjan como parte de los nuevos procesos de producción y reproducción social. Por ejemplo, en la época colonial, se habría producido un enorme impacto en las dos primeras décadas de la época colonial. Según Sempat Assadurian con el exterminio masivo de la población al parecer, se produce un enorme despoblamiento del área rural y su reconcentración alrededor de los centros mineros. (Sempat, 1982), el cual se recupera muy lentamente en base al nuevo sistema de pequeñas ciudades coloniales, que se fue construyendo sobre la base de la estructura pre hispánica. A su vez, Spalding señala que, los asentamientos humanos hispánicos, en Centroamérica y Sud América, se construyeron sobre las cabeceras de los pueblos pre hispánicos, los que en sus orígenes no eran unidades territoriales administrativas,

tropicales, la vida del pueblo o pequeńas ciudades de mercado. Tristemente, rural se asocia a menudo con versiones anteriores en las mentes de los residentes urbanos del mundo. Las comunidades rurales que viven incluso a distancias cortas, pueden ser muy diferentes en términos de clima, idioma, tradición y costumbres del entorno natural. Sin embargo, la población rural también tiene mucho en común. El principal medio de vida para la población rural en la mayoría de los países de ingresos bajos y medios es la agricultura, y lo seguirá siendo en el futuro previsible.». (Danert y Flowers:2002). Pero esta última afirmación, según se verá más adelante, ya no es tan sostenible, en varios países el mayor ingreso de la familia rural no proviene de la agricultura.

3 Diversos autores señalan que las disputas entre las comunidades rurales, en muchos casos tienen antecedentes históricos pre hispánicos, ligados con la organización de los Ayllus y la ocupación del territorio, luego son desestructurados con la conquista, las encomiendas y el trabajo forzado de la "mita", factores que motivaron «agravios» y conflictos entre las comunidades campesinas. Véase, por ejemplo, Poole, Deborah, A» Qorilazos, abigeos y comunidades campesinas en la provincia de Chumbivilcas, Cusco» en: "Comunidades campesinas. Cambios y permanencias", ediciones Solidaridad-Concytec., Chiclayo,1986, paginas 257-295 
sino que un pueblo podía tener distintas adscripciones geográficas, desplazándose para ocupar un territorio según sus necesidades productivas (Spalding, 1974).

Luego, desde el inicio de la república en 1821, el área o territorio urbano registra un lento proceso de diferenciación del área propiamente rural, en donde la mayoría de centros poblados aparecían como un complemento de la campiña o área rural, en la medida que la principal ocupación de las familias era la agricultura y la ganadería (mayor y menor). Al mismo tiempo que la población en general registraba tasas de crecimiento muy bajas, entre $1 \%$ a $2 \%$ anual. ${ }^{4}$

Dicha situación se mantuvo a lo largo del siglo xIx y las primeras décadas el siglo xx., en un contexto donde la modernidad expresada en el acceso a los servicios básicos como el gas y la electricidad para el alumbrado público, los servicios de agua y saneamiento, o las vías de comunicación, se desarrollaban lentamente en las urbes que concentraban la mayor población, tales como Lima, Arequipa, Trujillo, Cajamarca, Chiclayo, entre otras. Mientras que el área rural se caracterizaba por la carencia de tales servicios, al mismo tiempo que las condiciones de trabajo y de vida cotidiana de las familias campesinas, presentaban condiciones de pobreza; niveles educativos y hábitos de higiene, muy precarios.

\subsection{Lo urbano y lo rural entre 1900 y 1940}

En las tres primeras décadas del siglo $\mathrm{xx}$, el debate entre el espacio urbano y rural estuvo relacionado con las propuestas de políticas públicas, referidas a resolver lo que se denominaba como "el problema del indio», con distintos enfoques, bien sea desde un abordaje paternalista, como el de Riva Agüero, quien afirmaba que la suerte del Perú estaba indisolublemente ligada a la del indio y por lo tanto se debía mejorar la agricultura serrana (De la Riva Aguero, 1960), hasta los enfoques políticos, como los que se implementaban durante el gobierno de A.B Leguía, lo largo de los años veinte; y las propuesta socialistas de Mariátegui, en las que consideraba que el problema del indio era un problema económico, el cual tenía sus bases en la propiedad de la tierra en manos de los terratenientes feudales, y la extorsión del trabajo campesino, bajo relaciones de servidumbre. (Mariategui, 1928)

Las precarias condiciones de las clases populares en las provincias del interior y las condiciones de los habitantes rurales, se observan en la descripción que hizo Valcárcel(1981) sobre su ciudad natal, el Cusco, la cual tenía menos de quince mil habitantes; acerca de las condiciones de vida en los ańos veinte del siglo pasado.

4 Para una sinopsis histórica de la población y los Censos en el Perú, acuciosamente documentada, desde la época colonial y los primeros ańos de la república, véase: Arca (1944). 
«...la economía en Cusco estaba basada en su riqueza agrícola. La agricultura era el patrón de referencia de la vida humana, de la vivienda, del clima. etc. Las poblaciones dependían de la agricultura y estaban ubicadas en determinadas regiones en función de su producción. Por ejemplo, en las zonas cálidas casi no existían comunidades de indígenas que, por el contrario, eran numerosas en la zona de la puna.» (página 77)

La economía cusqueña dependía de la agricultura, pero al mismo tiempo, las transacciones comerciales en la feria semanal, combinaban el trueque entre productos con el dinero metálico, en donde los campesinos tenían una muy baja capacidad de acceso al dinero metálico. En efecto, según Valcarcel, (1981)

[...] En el mercado era corriente el uso del ají como moneda o «ranti» que quiere decir cambiar o contar. Con cinco centavos podían comprarse seis ajíes con los que, a su vez, podían adquirirse cosas distintas de poco valor. El ají hacía las veces de moneda fraccionaria, la gente humilde lo usaba mucho porque sus ingresos eran ínfimos...un peón, venido de fuera solo obtenía un jornal de 30 centavos diarios. (p. 53) [...] entre los indios era costumbre adquirir a través de intercambio de productos traídos de las zonas bajas; coca, ají, sal que provenía de Maras. Se intercambiaba maíz por ají, un carnero por determinada cantidad de coca o tarwi por habas [...].

A dichas relaciones desiguales en el mercado, se agregaban otras carencias como la falta de educación, de salud, de vías de comunicación, y de vivienda, que determinaban condiciones de vida muy precarias y en la extrema pobreza, en donde las condiciones de higiene eran unas de las más saltantes. Ello se puede apreciar en la descripción que hizo Valcárcel (1981) de las «chicherías».

[...] las chicherías populares, eran lugares en los que había que hacerse de mucha voluntad para entrar. Eran habitaciones oscuras de una pobreza decepcionante, desde cuyo exterior no podía verse nada salvo el fogón, pues lo demás, los muros y el techo estaban ennegrecidos por la capa de hollín que se había acumulado a través de los ańos, el piso era de tierra. Los alimentos se preparaban en la forma más antihigiénica imaginable y la chicha se fermentaba en las peores condiciones...lugares lúgubres y sucios donde los campesinos indios ahogaban sus frustraciones bebiendo fuertes cantidades de chicha o aguardiente...en las tres primeras décadas de este siglo...la falta de aseo siguió siendo la nota característica (p. 29).

La descripción de Valcárcel sobre el Cusco, no difiere en mucho de la apreciación que se tenía en los años veinte acerca de la situación del indio a nivel nacional, según se puede observar en los debates que se suscitaron durante el Primer Congreso de irrigación, que 
auspicio el gobierno de A.B, Leguía, en la ciudad de Lambayeque, el año 1929, en el cual se produce un debate sobre la condición del indio, señalando las condiciones de explotación en las que vivían en los latifundios de los terratenientes, pero al mismo tiempo se indicaban "características de la raza indígena», las que no eran comprendidas desde la cultura occidental, por ejemplo, Delgado (1929), describía las fiestas anuales que realizaban las comunidades campesinas, descritas como «eventos orgiásticos».

[...] La vida asociada de los grupos de la población aborigen peruana no existe. Desparramados sobre miles y miles de kilómetros cuadrados en un territorio de escasas y malas vías de comunicación, su vida como decimos antes es enteramente pastoril, casi nómada. Las comunidades o agrupaciones de indios mantienen poco trato frecuente entre ellos y por lo general están separados por vulgares pleitos domésticos y de intereses de terrenos y de ganado. la mayor asociación de comunidad de ideas lo hacen durante las fiestas religiosas, en la que se confunden en medio de orgias espantosas. (Delgado, 1929)

Se observa que una característica de la población y los centros poblados del área rural era su amplia dispersión, y su aparente falta de coordinación o interacción social, en tanto no se tenía un conocimiento de la cultura campesina y su reproducción desde las comunidades campesinas ancestrales, a lo que venía a sumarse las condiciones de trabajo de la población indígena

[...] en la sierra el abuso es mayor. El indio que no tiene terreno y se aviene a solicitar uno a cambio de su trabajo recibe apenas un espacio reducido para sembrar granos, no puede disponer de su ganado, porque el gamonal no se lo permite, y si dispone de él, tiene la obligación de venderlo al patrón, cundo este quiera y al precio que más le convenga. El, sus hijos, su mujer y toda su familia, son verdaderamente esclavos del hacendado, y jamás pueden abrigar ni la más remota esperanza de que su situación mejore... (Delgado, 1929, p. 274)

De esa manera, la corriente pro indígena que auspiciaba el presidente A.B. Leguía, a lo largo de los ańos veinte del siglo pasado, tenía entre uno de sus objetivos, el promover la parcelación individual de la tierra, buscando convertir al campesino indígena en un agricultor, o "farmer», como en la sociedad norteamericana. En ese aspecto, el principal consultor asesor del presidente Leguía, fue el ingeniero norteamericano Charles W. Sutton. Por ello mismo, el mencionado evento no podía concluir, sin una recomendación como la siguiente: 
[...] El Congreso de Irrigación y Colonización del Norte, comprendiendo la protección que sistemáticamente viene dispensando a nuestra raza aborigen el Gobierno el Perú, recomienda que se acentúe más esta protección; que se considere al indio como un factor decisivo de nuestra vida nacional, ya que es el mejor tipo de agricultor [...] la segunda consideración es que el Estado [...] debe dar un pedazo de tierra para él y los suyos... los inmensos latifundios de la sierra [...] forzosamente, deben parcelarse para que nuestros indios puedan ser ciudadanos... (Delgado, 1929)

En resumen, se puede concluir indicando que:

En las tres primeras décadas del siglo xx, el concepto de lo rural y la ruralidad, estaba relacionado con aspectos económicos: explotación en el latifundio, condiciones de trabajo serviles, predominio del mercado simple; aspectos sociales y culturales. comunidades dispersas, aislamiento geográfico, ausencia de servicios básicos (agua potable y energía), y ausencia de hábitos de higiene; aspectos demográficos: predominio de la población rural sobre la urbana, migración temporal del campo focalizada, hacia las minas, o las plantaciones industriales de la costa (azúcar y algodón, principalmente).

\subsection{Lo urbano y lo rural entre 1940 y 1970}

Desde mediados de los años veinte, durante el gobierno de A.B, Leguía el país inició un proceso de cambios económicos, políticos y sociales que contribuyeron en ampliar la urbanización en el país, el mismo que durante su gobierno se llamó «la patria nueva» (Cotler, 1978), proceso que continuarían los gobiernos siguientes, especialmente durante la dictadura de Odria y luego el gobierno de Manuel Prado, a mediados de los años cincuenta. En esas tres siguientes décadas comenzó también un proceso de urbanización intenso, producto de las masivas olas de migración, desde el campo hacia la ciudad, las que progresivamente cambiaron la estructura de la población en la ciudad de Lima, y luego en las otras ciudades importantes de la costa y algunas de la sierra.

En este periodo también se producen los primeros Censos Nacionales, con el objetivo de conocer las características demográficas del país, y sus diferencias entre lo urbano y lo rural. En 1940 se realizó el Censo Nacional y Población, el cual fue dirigido por Arca Parró (1944), quien no solo diseño una metodología censal muy acuciosa, sino que también movilizó amplios sectores de la población, para llenar y/o complementar la ficha censal. Precisamente, uno de los temas claves en la ficha fue la definición de «Centro poblado» (Arca, 1944)

[...] toda localidad era anotada con indicación de su nombre, categoría, población estimada, distancia y clase de vía de comunicación a la capital distrital y, además los nombres de dos personas con mayor grado de instrucción (posibles colaboradores del 
censo).Para uniformizar el criterio de los organismos informantes acerca de la amplitud del término "Centro poblado», la Dirección del Censo formulo oportunamente la siguiente regla: «para los efectos del Censo, se conoce con la denominación genérica Centro Poblado a todo lugar o sitio del territorio peruano en el que varias o muchas personas, sean o no parientes, establecen sus casas, chozas o campamentos permanentes y viven habitualmente en aquellas, dedicándose a una o varias actividades económicas, sean estas agrícolas, ganaderas, pesqueras, mineras, comerciales, industriales o de otra orden. (p. LI)

De esa manera el Censo de 1940, registra una población total de 6.2 millones de habitantes, de los que un $73 \%$ residían en el área rural, mientras que solo un $26.9 \%$ era población urbana. Dicha situación se modificará de manera sustantiva, al reducirse la población rural a un $60 \%$, y la urbana se incrementaba hasta un $40 \%$, según se observa en el cuadro 1.

\section{Cuadro 1}

Perú, crecimiento y distribución de la población (miles de habitantes)

\begin{tabular}{lcccc}
\hline \multicolumn{1}{c}{ Población } & 1940 & $\%$ & 1961 & $\%$ \\
\hline Total & 6.208 & 100 & 9.906 & 100 \\
\hline Rural & 4.537 & 73.1 & 5.933 & 59.9 \\
\hline Urbana & 1.671 & 26.9 & 3.973 & 40.1 \\
\hline
\end{tabular}

Fuente: (Cotler, 1978) P. 239

Dichas modificaciones en el conjunto de la población rural, se expresarán también en el porcentaje de población que residía en los centros urbanos. En efecto, en el cuadro 2 se observa que, en 1940, apenas medio millón de habitantes residían en un centro poblado con más de cien mil habitantes, dicha proporción se triplicará dos décadas después, llegando a residir casi dos millones de habitantes en centros poblados con más de 100 mil habitantes.

\section{Cuadro 2}

Perú, crecimiento y distribución de la población urbana (miles de habitantes)

\begin{tabular}{lcccc}
\hline \multicolumn{1}{c}{ Tamaño del CP } & $\begin{array}{c}\text { Habitantes } \\
1940\end{array}$ & $\%$ & $\begin{array}{c}\text { Habitantes } \\
1961\end{array}$ & $\%$ \\
\hline Centros de 2-5000 & 390 & 6.3 & 508 & 5.1 \\
\hline Centros de 5-20000 & 373 & 6.0 & 652 & 6.6. \\
\hline Centros de 20- 100 000 & 388 & 6.2 & 860 & 8.7 \\
\hline
\end{tabular}

Fuente: (Cotler, 1978) 
El crecimiento de la población urbana, especialmente en la ciudad capital, alcanzara cifras espectaculares en los años sesenta, pasando de 1.8 millones en 1961 a 3.3. millones en 1972, y 4.6 millones en la década siguiente, debido principalmente a la ola migratoria del área rural hacia el área urbana. Así mientras que la tasa promedio anual intercensal nacional, fue de 2.9 entre 1961-1972, y de 2.5 entre 1972-1981; en cambio, en Lima Metropolitana fue de 5.5. y 3.7, respectivamente. (INE, 1983). pero dicho proceso migratorio no solo tendrá impacto en la capital, sino también en las principales ciudades de las diferentes regiones del país. Por ejemplo, según Martínez (1983) en los departamentos el sur peruano, como Puno, Arequipa, Tacna, Apurímac, existía una larga tradición de movilización y migración de la población rural y urbana, que fue documentada desde la época colonial (La visita a Chucuito de 1567), hasta la época republicana (Raimondi, en 1876), y una amplia documentación en los años sesenta. del siglo xx. (Martinez, 1983), y sobre la población rural específicamente señala que:

[...] en 1940 se observa que solo el 7\% de la población regional estaba comprometida en el fenómeno migratorio [...] [Pero] en 1961 la población migrante representaba el 25\% del total regional, en 1972 había llegado al 31\% [...] en cifras absolutas significa que de una población migrante de 130 mil en 1961, se pasa a 526 mil en 1972, es decir un aumento del 305\%. ( (Martínez, 1983, p. 217)

Cabe indicar que, al mismo tiempo que se producían los desplazamientos de la población, del campo hacia la ciudad, ocurrían otros fenómenos económicos, sociales y políticos, que influenciaban la visión que se tenía del área rural. Sin modificar de manera sustancial la visión de la etapa anterior (1900-1930), se agregaban otros elementos metodológicos para definir la ruralidad, por ejemplo, las características del desarrollo nacional, influenciada por la teoría desarrollista, la cual dividía a los países en desarrollados y subdesarrollados, en donde los segundos se caracterizaban por «el estancamiento de la economía rural» (Aramburu, 1983), aspecto que definía las características de la fuerza laboral, de las formas de propiedad y tenencia de la tierra, hasta los aspectos demográficos tales como la natalidad y mortalidad, en el área rural. (Pecht, 1974).

En los años sesenta y setentas, el énfasis de los autores se enfocaba en comprender las formas como el desarrollo capitalista transformaba, o no, las estructuras agrarias, y con ello se modificaba el área rural. En ese sentido los países más estudiados eran Brasil y México. Sin embargo, desde los años sesenta ya se advertían las dificultades que había para establecer los urbano y lo rural en los distintos países. Según Unikel (1968), las Naciones Unidas, identificaron más de treinta criterios usados para definir lo urbano, por lo cual destacaba: 
[...] Lo infructuoso de los esfuerzos realizados por Naciones Unidas por unificar los criterios censales para definir población urbana, se manifiesta en la recomendación con relación al censo de 1970, que dice: «en vista de las diferencias nacionales en las características que distinguen las áreas urbanas de las rurales, la distinción entre la población urbana y la rural no es todavía factible de englobarse en una sola definición que pueda ser aplicable a todos los países. (Naciones Unidas, Principies and Recommendations for the 1970 Population Censuses, Statistical Papers, Serie M, Núm. 44, 1967, p. 63. Unikel, 1968, p. 4)

\subsection{El área rural entre $1970-2010$}

Las dificultades que observaron las NNUU en los años sesenta, para poder clasificar a la población según áreas urbana y rural, se han mantenido a lo largo del tiempo, hasta el presente. Aspecto que es advertido por distintos autores. Por ejemplo, el Banco Mundial (2005), sugería que, para una mejor comprensión de lo rural, se podría usar el criterio de la densidad demográfica inferior a 150 personas por $\mathrm{km} 2$, y una distancia a zonas urbanas más importantes superiores a una hora. (Banco Mundial, 2005) Por su lado, desde la CEPAL (2011) se realizó una revisión de las estadísticas usadas en los distintos países de América Latina y ratificaban la conclusión de su gran heterogeneidad, (CEPAL, 2011) y se sugerían nuevos criterios para la definición de lo rural (Sabalain, 2011).

Por ello es importante para comprender el proceso histórico, del desarrollo local y regional, en donde una de las variables será las condiciones de conectividad, de intercambio y movilización con los centros urbanos más cercanos, en donde la categoría «tiempo de traslado», para movilizarse de un lugar a otro, de lo rural a lo urbano, también puede tener distintas definiciones. Las dificultades para adoptar definiciones más o menos homogéneas fue advertida desde hace varias décadas. Según Danert \& y Flowers, (2012), a la fecha,

No existe una definición comúnmente aceptada de la población urbana. Los métodos varían según los países. Urbano se puede denominar en términos de etiquetas como «grandes ciudades», «municipios» o «centros administrativos» o el uso de un umbral cuantitativo (por ejemplo, las poblaciones más 2000 en varios países de América Latina y de África Occidental; encima de 200 en Islandia y más de 10.000 en Italia y Benín. En algunos casos definiciones socioeconómicas complejas se utilizan para definir urbana (ONU 2004). En otros casos no existe una clasificación oficial de la población urbana (Potts 2012). Estas diferencias nacionales se reflejan en las estadísticas mundiales mantenidas por las Naciones Unidas (FAO, 2005). 


\section{La definición de lo rural en el Perú, según los censos}

Según se ha indicado, la definición de espacio urbano y rural en la mayoría de países es difícil porque la definición de lo uno, se hace por defecto con el otro; pero en general se adoptan criterios cuantitativos y/o cualitativos.

En términos generales, se reconoce que América Latina se caracteriza por ser una de las regiones más urbanizadas del mundo, donde cerca del 78\% de la población vive en contextos urbanos, en términos cuantitativos, países como Venezuela, Uruguay, Argentina, Colombia y Chile, cerca del $90 \%$ de su población es urbana. Pero, los criterios para determinar lo urbano difieren de un país a otro, así por ejemplo, mientras en Venezuela y México se considera urbana a los centros poblados con 2.500 o más habitantes; en países como Argentina, Colombia o Bolivia se considera urbana a centros poblados de 2.000 habitantes; en Ecuador y Costa Rica se considera urbano a los centros administrativos de provincias y cantones, y en Nicaragua a aglomeraciones de 1.000 habitantes, siempre que cuenten con características urbanas como electricidad y comercio ${ }^{5}$.

El paisaje rural, estudiado por la geografía rural, incluye también las zonas dedicadas a otros usos tales como residenciales, industriales, de transporte o de servicios, en divisiones territoriales clasificadas previamente como rurales, de acuerdo al tamańo de su población.

La definición del área rural, según se ha mencionado, fue establecida por las entidades encargadas de realizar los censos nacionales. (Arca Parro, 1944), la misma que se han venido perfeccionando en los tres últimos censos nacionales. En 1972, la Oficina Nacional de Estadísticas y Censos (ONEC), definía lo rural de la siguiente manera: «Área rural es la parte del territorio de un distrito, que se extiende desde los linderos de los centros poblados en área urbana, hasta los límites del mismo distrito».

A su vez, el área urbana se definía como: «Es toda aglomeración, cuyas viviendas en número mínimo de 100 se hallan agrupadas contiguamente. Por excepción se consideró como urbanas a todas las capitales de Distrito. La aglomeración puede contener uno o más centros poblados con viviendas contiguas.»

Cabe recordar también la definición que se hacía de centro poblado con viviendas juntas: «Se considera que un centro poblado tiene sus viviendas contiguas o juntas, cuando estas se hallan agrupadas (unidas o colindantes) o distanciadas unas de otras, por lo menos 30 metros». (ONEC, 1972 )

5 F: http://www.geocensos.com/2011/06/como-de-determinan-las-areas-urbanas-y.html Los rasgos característicos poblacionales del espacio urbano son su alta densidad, su menor extensión y la dotación de todo tipo de infraestructuras; además de la particularidad de las funciones propias urbanas, especialmente las económicas, concentrándose la actividad y el empleo en los sectores secundario y terciario, con menos participación del sector primario. 
Sin embargo, para efectos de presentar las estadísticas nacionales según criterios de población rural y urbana, el país adoptó las recomendaciones de las Naciones Unidas, en el sentido de hacer un corte en la agregación de la población y considerar como población rural a toda la población que resida en centros poblados, villorrios y comunidades con menos de 2,000 habitantes. Criterio que fue usado para todos los efectos de las políticas públicas. Por ejemplo, el Ministerio de Trabajo, en convenio con las Naciones Unidas, en el año 1978, establecía una definición de lo «urbano» y "rural», desde el tamaño poblacional:

Se considera urbana, aquella población que habita conglomerados de 2,000 y más habitantes; y rural a la que habita en Centros poblados menores de 2,000 habitantes. (de esa manera encontraban que) la población rural tenía una disminución notable, expresada de en forma descendente desde 1940 en que era el 73\% de la población nacional, a un 59\% en el año 1961 y finalmente a un $47 \%$ en el año 1972. (Ministerio de Trabajo, 1978)

En el Censo Nacional de 1981, las definiciones generales de la cédula censal, definían el área rural, el área urbana y el centro poblado de la siguiente manera:

Área Rural: es el conjunto de centros poblados que tienen menos de cien viviendas agrupadas contiguamente o están distribuidas en forma dispersa.

Área Urbana: Es el conjunto de centros poblados que tienen como mínimo 100 viviendas agrupadas contiguamente o son capitales de distrito. El área urbana de un distrito puede estar conformada por uno o más centros poblados.

Centro Poblado: Es todo lugar o sitio del territorio nacional identificado mediante un nombre, en el que viven con ánimo de permanencia, por lo general varias familias, por excepción una sola familia o una sola persona. Las viviendas que ocupan las personas pueden hallarse contiguas formando calles, plazas, como es el caso de los pueblos, ciudades; o bien semi dispersas y con un pequeńo grupo de viviendas agrupadas contiguamente, como es el caso de algunos caseríos, rancherías, etc; o hallarse totalmente dispersas, como, por ejemplo, las viviendas de los agricultores en las zonas agropecuarias. (INEI, 1983, p. 41)

En la década de los noventa, el INEI ejecuta en forma las Encuestas Nacionales de Hogares con las que se identifican indicadores sociales. La población de los estudios en las Encuestas incluye a los hogares y sus habitantes residentes permanentes, en unidades de vivienda del área urbana y rural del país. En dichas encuestas: "Se define como población urbana a la población residente en los centros poblados con 2,000 y más habitantes y como rural a aquellos centros poblados con menos de 2,000 habitantes». (INEI, 1998) 
De esa manera, las ENAHO, han definido su marco maestral y sus Unidades de Muestreo, de la siguiente manera:

- Área urbana: La Unidad Primaria de muestreo (UPM) es el centro poblado urbano con 2,000 y más habitantes.

- Área rural: La unidad primaria de muestreo es de dos tipos: el Centro Poblado urbano con 500 a menos de 2,000 habitantes. Y el Área de Empadronamiento Rural (AER) el cual tiene en promedio 100 viviendas particulares (INEI, 1998).

Con lo cual para el INEI lo estrictamente rural (Área de empadronamiento rural) sería sólo aquella que tiene en promedio 100 viviendas juntas o 500 habitantes.

Sin embargo, en el Perú, el debate acerca de la definición de o rural y sus alcances fue recurrente en el ámbito académico, aunque con énfasis en la estadística o argumentos cuantitativos, bien sea a partir del tamaño de las localidades (Maletta,1978) o, desde un enfoque del desarrollo de la agricultura en el Perú (Hopkins, 1981) En efecto, desde fines de los años setenta hubo un debate entre los académicos y el INEI, acerca de la definición de «lo rural» como parte del debate para determinar los niveles de urbanización y de migración rural hacia el área urbana en esas épocas.

\section{Los debates sobre la población rural}

Como se ha indicado, las dificultades que observaron los investigadores sociales, en la definición de la ruralidad, ha sido un debate permanente en las distintas disciplinas. Uno de los temas que se discutía era acerca de la "Densidad de la población» (Urzua, 1979), con distintos niveles de desagregación territorial según los países, incluyendo unidades más pequeñas que las político-administrativas (distritos, fracciones, segmentos o áreas de empadronamiento). Por ejemplo, identificar las localidades con 100 habitantes por Klm. Cuadrado, según la metodología que usaba las $\mathrm{NNUU}^{6}$; de allí que desde los años sesenta, Unikel (1968), advertía las dificultades que había en México, para categorizar a la población urbana, y rural, sugiriendo más bien ampliar los criterios en el tamaño, hasta 5,000 habitantes., entre otros factores. Por su lado Pecht (1974), haciendo una comparación entre México y Brasil, también observó dichas limitaciones, analizando el desarrollo agrícola y el crecimiento de la población.

6 En los documentos de las NNUU sobre la población, y sus diferencias entre lo urbano y rural, desde los años sesenta se consideraba que: «el 34\% del total de la población de América Latina y El Caribe vivía en 1970, en unidades administrativas de menos de 25 personas por Km cuadrado, que const ituye el mínimo que las NNUU considera necesario para que existan relaciones sociales y culturales así como para que se realicen actividades económicas diversificadas», en : Urzúa Raúl: 1979. 
En el Perú, según se indicó anteriormente, a fines de los años setenta hubo un breve debate acerca de la ruralidad en el Perú, entre Maletta y Aramburu (1979), implicando el tamaño de la población en las localidades, las características de la Población Económicamente Activa (PEA), el crecimiento de la agricultura de exportación, y al mismo tiempo la continuidad y las relaciones no capitalistas en el campo, y los cambios en la educación formal, entre otros. Según Maletta (1978):

[...] hacia 1961 la situación iba cambiando aceleradamente: el porcentaje «rural» había bajado de 64.6 a un 52.5\%; mientras correlativamente la población urbana se aproximaba ya a la mitad de la población total en 1972, fecha del siguiente Censo, ya la población urbana era mayoritaria (59.5\%), e incluso lo era si se tomaba como umbral los dos mil habitantes, pues entonces el porcentaje resultaba del 53.17\%. (Maletta, 1978).

Según el citado autor, en los años setenta el país había alcanzado un alto grado de urbanización y en consecuencia, una disminución de la ruralidad. Algunas de sus conclusiones eran las siguientes:

- Entre 1940 y 1970 se inicia en el Perú un intenso proceso de urbanización que altera de manera profunda la proporción rural/urbana.

- La población rural tiende a estancarse en su crecimiento a partir de los años sesenta.

- En algunos sectores académicos se tiende a subestimar el tamaño de la población urbana a sobre estimar la población rural y campesina. Los campesinos se definen como productores agrícolas, y/o artesanos, y comerciantes, tienen una economía familiar, sustentada en el trabajo de todos los miembros de la familia, quienes trabajan con sus propias herramientas.

- Pero, las familias campesinas son objeto de relaciones asimétricas de extracción de excedentes desde el Estado, los terratenientes o los comerciantes.

- No se puede igualar "poblador rural» con "población campesina». la población rural está compuesta por todos los miembros de la familia, mientras que campesinos podrían ser uno o dos miembros.

- Los campesinos generalmente son adscritos a una cultura comunal, al margen del mercado, pero esa situación está cambiando de manera muy rápida. Uno de los factores para ello es la mayor difusión de la escuela rural y la disminución de las abismales tasas de analfabetismo, así como la ampliación de las relaciones salariales en la producción agrícola. (Maletta, 1978)

Aspectos que era cuestionado por (Aramburu C, 1978), según lo cual:

- Aceptando en términos generales las cifras acerca del proceso de urbanización, cuestiona la idea de la "desintegración campesina». 
- Cuestiona el contenido el concepto de la urbanización que Maletta adscribiría a una urbanización clásica, sin considerar los procesos de "marginalidad", informalidad, tercerización, etc a las que es sometida la fuerza laboral migrante de origen campesino en las ciudades.

- Aramburu señalaba que para comprender «el mundo rural peruano» se debía analizar las formas de producción no capitalistas, o lo que se denominaba las formas de reproducción mercantil simple.

- Cuestiona el que Maletta haya excluido a los «trabajadores familiares no remunerados» en la estimación del campesinado, porque esta forma de trabajo es la que le permitiría a la familia campesina su sobrevivencia

- En oposición a Maletta, destaca las distintas ocupaciones de la familia campesina, como una "estrategia de sobrevivencia», ello incluye la migración estacional a las ciudades.

- Finalmente, destaca la importancia de los factores culturales en la reproducción de las familias campesinas, y considera que es un error el considerar que el aprendizaje de la lectura y escritura, es suficiente para dejar de ser campesino. (Aramburu, 1979)

Tales comentarios tuvieron una respuesta de Maletta (1979), también en términos cuantitativos, para demostrar los avances en la urbanización, y las correcciones que se debían hacer a algunas estadísticas y cifras oficiales; y se ratificaba en que para operacionalizar las cifras de los campesinos, lo más útil era adscribirlos al concepto de "productor agrícola», población cuyos ingresos y gastos eran dependientes del mercado local, y por lo tanto, las relaciones pre capitalistas (serviles y comunales), argumentadas por Aramburu, estarían disminuyendo drásticamente. (Maletta, 1979)

En conclusión, se puede decir que el debate acerca de la ruralidad ha tenido de manera constante a la residencia de la población, según el tamaño, a uno de sus referentes más importantes. En base a las estadísticas de los censos nacionales y de otras instituciones relacionadas con el sector agrario, se ha validado la percepción común de que una localidad es rural si tiene menos de dos mil habitantes. Esta apreciación cuantitativa solo es complementada en menor medida con análisis de los factores sociales, económicos o culturales, a fin de establecer una definición de la ruralidad.

\section{Los cambios en la ruralidad y la «Nueva ruralidad»}

Según se ha argumentado en los acápites anteriores, el área rural en el Perú ha experimentado cambios significativos en las últimas décadas. La definición del área rural, según los censos nacionales, se han perfeccionado en los últimos censos nacionales, para 
dar cuenta de los procesos demográficos, el crecimiento cuantitativo de la población, de algunas características sociodemográficas, y de las migraciones, entre otras. Pero, la ruralidad y el espacio rural en su definición, además de esos elementos, requiere incorporar otros factores que permitan dar cuenta, o informarnos acerca de las condiciones sociales, culturales y económicas de lo que se está considerando como rural.

En ese sentido, la visión de la ruralidad hasta fines de los años sesenta, registraba la modificación de algunos patrones o tendencias de comportamiento, tales como el inicio de procesos de migración del campo a la ciudad más intensos, o modificaciones en algunas áreas de la producción agrícola, por ejemplo la dedicada al mercado interno, mientras que en otras hubo estancamientos y ciclos de auge (Hopkins, 1981).Pero en el tema de la conectividad, es muy relevante el incremento de carreteras asfaltadas en el periodo 1940-1960 casi se duplica, pasando de 25 mil kilómetros a más de 45 mil kilómetros. En las décadas siguientes el sistema de carreteras se fue mejorando y en el año 2002 se tenía a nivel nacional 79,320 kilómetros de red vial, pasando en el año 2009 a 126,500 kilómetros de red vial, según la cual, las carreteras que más se incrementan son los caminos vecinales, los que el año 2002 representaban un 58\%, pasando a representar el 62\% en el año 2009 (INEI, 2010). Estos cambios en la vialidad serán uno de los factores claves para el surgimiento de la «Nueva ruralidad», como se verá en el acápite siguiente.

A su vez, diversos autores han destacado los cambios estructurales que se producen en el país, a partir de 1969 con la Reforma Agraria decretada por el general Juan Velasco, cuyos efectos sobre el área rural serán directos, en cuanto a la propiedad y tenencia de la tierra, y en las relaciones sociales de producción. En general los grandes latifundios fueron expropiados, se liquidaron las relaciones serviles que predominaban principalmente en el latifundio de la sierra. Según el CEPES (1989).

[...] La reforma agraria debe ser observada como un fenómeno social y económico orientada hacia la democratización y generación de las condiciones para un mayor desarrollo del mercado interno. Las relaciones sociales pre capitalistas sustentadas en la permanencia de las haciendas tradicionales, fueron cambiadas; gran parte de las tierras expropiadas fueron entregadas a los trabajadores agrícolas organizados en cooperativas; la lógica de acumulación y organización de la economía, sujeta en gran medida a los intereses de la gran burguesía propietaria de tierras, fue quebrada. (CEPES, 1989)

No obstante, el rápido proceso de expropiación de los latifundios, las relaciones sociales en el campo tomaron más tiempo en modificarse, porque las estructuras de poder local no fueron afectadas. En las pequeñas ciudades del interior y en las comunidades campesinas, continuaron predominando pequeñas elites, que administraban el poder según sus intereses particulares. (Mayer,1988, citado por Eguren,1989) 


\subsection{La «nueva ruralidad» en el Perú}

Diversos autores han advertido los cambios sociales, económicos y políticos que se registran en la mayoría de países de LAC, desde las tres últimas décadas y, han sugerido el concepto de «Nueva ruralidad» para comprender las nuevas características que asume el espacio rural, principalmente en su interrelación con el área urbana. (De Grammont, 2008), y los desafíos que estos cambios demandan a las políticas públicas, especialmente en la provisión de servicios básicos (Mejia, Castillo, Vera, \& Arroyo, 2016) para las comunidades rurales.

Cabe indicar que, en el Perú, Webb (2013), es uno de los autores que ha observado con detenimiento los cambios producidos en el área rural del Perú. Su argumento es que la principal traba para luchar contra la pobreza es la dispersión de la población, dado que, en el país, existen más de ochenta mil centros poblados dispersos, con menos de treinta viviendas juntas. Ese abordaje, de alguna manera va a contra corriente de las tradicionales afirmaciones para explicar el atraso rural, en el último medio siglo, como producto de "políticas públicas de apertura comercial»,» el tipo de cambio», "fijación de precios y subsidios», "registros de propiedad», entre otros, pero con una escasa referencia a la geografía. (Webb, 2013), y en base a un amplio estudio de campo, el mencionado autor encuentra que:

La dispersión residencial esta correlacionada con productividad. Moverse de una residencia rural a un pueblo pequeño (entre 401 a 4,000 viviendas) aumenta la productividad en $89 \%$.

La dispersión residencial esta correlacionado con indicadores de bienestar. El déficit de servicios públicos aumenta con el grado de ruralidad, el informe se refiere a distancia y/o tiempos de viaje; y tamaño del centro poblado

El estudio encuentra una alta correlación entre ruralidad y productividad. La productividad medida por el ingreso laboral del hogar, guarda una estrecha relación con el grado de aglomeración residencial, doblándose al pasar de una residencia rural a un pequeño centro de menos de 4,000 hogares, y casi doblándose nuevamente al pasar del centro poblado a Lima.

Se observa la alta prioridad que las comunidades andinas, asignan a los caminos. El equipo de Webb visitó cinco provincias: Chumbivilcas, Acobamba, Cotabambas, Pachitea y Celendín, y 38 distritos seleccionados por su extrema pobreza y alejamiento; encontrando evidencias del dinamismo económico, inversiones en la construcción reciente, mejoras tecnológicas, aumento de jornales, cultura empresarial, activismo municipal, ferias, tráfico de carga y pasajeros, acceso a celulares, televisión por cable e internet y negocios nuevos en los centros poblados

Luego, una encuesta en 224 distritos rurales de alta pobreza, encontró un alto nivel de reducción de tiempos de viaje, desde el distrito hacia una ciudad, se había reducido 
en un 57\%, es decir de 9 horas, bajo a 4 horas, en solo diez años; así mismo, la elevación de jornales, elevación del valor de la tierra agrícola, y elevación del valor de las viviendas en las capitales distritales

La mejora comunicativa es casi explosiva desde los años noventa. La reducción en más del $50 \%$ en el tiempo de viaje, entre las capitales de distrito y las ciudades, está ligada con la multiplicación en la construcción de caminos, principalmente desde el ańo 1994, triplicando el kilometraje construido anualmente; a ello se agrega la masiva difusión del teléfono celular, en el área rural, donde la proporción de hogares que los poseen aumentó de 2\% en el año 2005, a más de un 50\% en el 2012. (Webb, 2013)

\section{Conclusiones}

En base a esta revisión bibliográfica rápida, en la que se identifican tres periodos importantes, para conocer las características de la ruralidad, se puede decir que:

El espacio rural necesitara nuevas herramientas metodológicas para su definición; al mismo tiempo que la tradicional mirada de la ruralidad, solo desde las estadísticas de población, ya no es sostenible.

Para conocer el espacio rural, y sus nuevas relaciones con la ciudad o el área urbana, se necesitará incluir otras variables tales como: i) Densidad de la población, calculada con distintos niveles de desagregación territorial (distritos, fracciones, o áreas de residencia), identificar las localidades con 100 habitantes por Klm. Cuadrado. ii)Tamańo de la población: localidades con menos de 2.000, y hasta 5.000 habitantes. iii) Distancias en tiempo de recorrido a centros poblados urbanos: de dos a cuatro horas, mediante carreteras secundarias y/o caminos rurales. iv)Tipo de ocupación o empleo, que predomina en el territorio, y la actividad principal (agropecuaria, forestal, minera) con la residencia de sus habitantes. iv) Identificar las principales fuentes de ingresos de los hogares rurales, y vii) Identificar las características culturales, que diferencian a la población rural de la urbana. viii) Identificar las áreas de población rural concentrada, y las áreas de población dispersa (pueblos o villorrios con menos de treinta viviendas juntas). ix)Finalmente, identificar el papel del Estado y las políticas públicas contra la pobreza.

Los tres periodos brevemente analizados, acerca de la ruralidad en el Perú, presentan diferencias en sus definiciones, y también continuidades, las que probablemente estarán presentes en la definición de la Nueva ruralidad, un concepto que se construye desde el presente. 


\section{Referencias}

Aramburu, C. (1979). El campesinado peruano, critica a Maletta. Análisis, Cuadernos de Investigación, No 8-9, mayo-diciembre, 109-135.

Aramburu, E. (1983). Las migraciones en la sociedad campesina. En A. M. AMIDEP, El Sur peruano: realidad poblacional (págs. 243-257). Lima: Amidep.

Arca Parro, L. (1944). Censo Nacional de Población y ocupación,1940. Lima: Ministerio de Hacienda y Comercio. Dirección Nacional de Estadisticas.

Banco Mundial (2005). Más allá de la ciudad: el aporte del campo al desarrollo. Washington: Banco Mundial.

Ceballos, H., \& y Ceballos, D. (2006). Categorías del tiempo histórico. Endoxa, Series Filosóficas No 21, 137-156.

CEPAL (2011). Hacia una definición de lo rural con fines estadisticos en América Latina. Santiago de Chile: Comisión Económica para America Latina, CEPAL, Editado por: Martine Dirven et al.

CEPES (1989). Editorial. Debate Agrario. Análisis y Alternativas. Revista del Centro Peruano de Estudios Sociales, 5-8.

Cotler, J. (1978). Clases, Estado y nación en el Perú. México DF: Universidad Nacional Autónoma de México.

Danert, K., \& y Flowers, C. (2012). People, Politics, The Envorinment and Rural Water Supplies. Berna, Switzerland: RWSN, Rural Water Supply Network, Volumen 1.

De Grammont, H. (2008). El concepto de nueva ruralidad. En E. Pérez, La nueva ruralidad en América Latina. Avances teóricos y evidencias empiricas. Bogotá, Colombia: CLACSO, Pontificia Universidad Javeriana.

De la Riva-Agüero, J. (1960). Afirmación el Perú. El Perú en su historia, Vol I y II. Lima: Publicaciones del Instituto Riva-Aguero.

Delgado, M. L. (1929). La población en el Perú. Anales del primer congreso de Irrigación y colonización del Norte 19 al 24 de febrero de 1929, Vol I (págs. 273-276). Lima: Imprenta Torres Aguirre.

Hopkins, R. (1981). Desarrollo desigual y crisis en la agricultura peruana 1944-1969. Lima: Instituto de Estudios Peruanos, IEP.

INE, I. N. (1983). Perú, compendio estadístico, 1982. Lima: Dirección General de Estadísticas Básicas.

INEI (1983). Censos Nacionales, VIII de población, III de vivienda, 1981. Resultados definitivos.Departamento de Lambayeque, Volumen A. Lima: Instituto Nacional de Estadísticas y Censos.

INEI (1998). Como se miden las condiciones de vida? Lima: Instituto Nacional de Estadísticas y Censos, INEI, documento 22 páginas. 
INEI. (2010). Perú, compendio estadístico, 2010, Tomo 2. Lima: INEI, Sistema Estadistico Nacional. Instituto Nacional de Estadísticas e Informática.

Maletta, H. (1978). Peru,pais campesino?,aspectos cuantitativos de su mundo rural. ANALISIS, Cuadernos de Investigación, No 6 setiembre-diciembre,Lima, 3-54.

Maletta, H. (1979). «El discreto encanto del campesinado, replica a Aramburu». Análisis, Cuadernos de Investigación, No 8 y 9, Lima, mayo-setiembre, 109-158.

Mariátegui, J. C. (1928). 7 ensayos de interpretación de la realidad peruana. Lima: Biblioteca Amauta.

Martínez, H. (1983). Migraciones internas en la región sur. En A. M. AMIDEP, El Sur peruano: realoidad poblacional (págs. 215-240). Lima: AMIDEP.

Mejía, A., Castillo, O., Vera, R., \& Arroyo, V. (2016). Agua Rural.Agua potable y saneamiento en la nueva ruralidad de América Latina. Bogotá, Colombia: CAF,Banco de Desarrollo de América Latina.

Ministerio de Trabajo (1978). Industrialización, empleo y migración interna en el Perú (Tomo II). Lima: Ministeriuo de Trabajo-FNUAP, Proyecto PER/75/PO4. M.T Dirección General de Empleo, 191 páginas.

ONEC, O. N. (1972, ). Censos Nacionales VII de Población, II de vivienda. Lima: ONEC.

Реснт, W. (1974). Estructura agraria y dinámica de población. El sector rural en Brasily México, un enfoque de las relaciones entre el desarrollo agricola y el crecimiento poblacional. México DF: Cenytro Latinoamericano de Demografía, CELADE.

Rajchenberj, S. E., \& Lambert y C. (2002). Tiempo,calendario y relojes. Estudios Sociológicos Vol XX, No 2, CES COLMEX, 287-303.

Sabalain, C. (2011). El concepto de lo rural en los paises de la región. En C. Comisión Económica para América Latina, Hacia una definición de lo rural con fines estadisticos en América Latina (págs. 21-29). Santiago de Chile: CEPAL.

Sempat, A. (1982). El sistema de la economía colonial. Mercados internos, regiones y espacio económico. Lima: Instituto de Estudios Peruanos, IEP.

SPALDING, K. (1974). De indio a campesino. Lima: Instituto de Estudios Peruanos, IEP.

Unikel, L. (1968). Ensayo sobre una nueva clasificación de la población rural y urbana en México. Demografia y Economía, Revista del COLMEX, Vol 1, No 1, 1-18.

Urzua, R. (1979). El desarrollo y la población en América Latina. México DF: Programa de Investigaciones Sociales sobre Población en América Latina (PISPAL),Ed. Siglo XXI.

Valcárcel, L. E. (1981). Memorias. Lima: Instituto de Estudios Peruanos, IEP, editadas por J. Matos Mar, José Duestua, José Luis Renique.

Webb, R. (2013). Conexion y despegue rural. Lima: Universidad San Martín de Porres, USMP. Fondo Editorial.Instituto Perú. 